\title{
Acute ST-elevation myocardial infraction after use of oral sumatriptan: a rare presentation
}

\author{
Indira Sahu ${ }^{1 *}$, Manish Ruhela ${ }^{2}$, Rakesh Kumar Ola ${ }^{2}$
}

\author{
${ }^{1}$ Medical Officer, CHC, Laxmangarh, Sikar, Rajasthan, India \\ ${ }^{2}$ Department of Cardiology, Noble Care Hospital, Sikar, Rajasthan, India
}

Received: 16 September 2020

Accepted: 12 October 2020

\author{
*Correspondence: \\ Dr. Indira Sahu, \\ Email: dr.indirasahu@gmail.com
}

Copyright: $(\subset)$ the author(s), publisher and licensee Medip Academy. This is an open-access article distributed under the terms of the Creative Commons Attribution Non-Commercial License, which permits unrestricted non-commercial use, distribution, and reproduction in any medium, provided the original work is properly cited.

\begin{abstract}
Sumatriptan is an agonist of 5-hydroxytryptamine type-1 (5HT1) receptors that is widely used as a migraine abortant; however, there have been studies showing angina, coronary vasospasm, and even myocardial infraction in patients with predisposing cardiac risk factors. We present the case of a female patient with no cardiovascular risk factor who developed ST-elevation myocardial infraction 30 minutes after ingesting oral sumatriptan for her migraine.
\end{abstract}

Keywords: Sumatriptan, Migraine, Myocardial infraction

\section{INTRODUCTION}

Sumatriptan is an agonist of 5-hydroxytryptamine type-1 (5HT1) receptors that is widely used in the treatment of migraine. It improves migraines symptoms through intracranial vasoconstriction, mediated by inhibition of neuroinflammatory peptide release. ${ }^{1}$ Sumatriptan and other 5-HT1 receptor agonists cause a sensation of chest tightness without electrocardiographic abnormalities in $3 \%$ to $5 \%$ of patients, and more rarely might provoke myocardial ischemia or cardiac dysrhythmia. ${ }^{2-4}$

Thransmural myocardial infraction after triptan use is rare, and in all reported cases to date, it has occurred after parenteral administration or in patients with atheromatous coronary artery disease. ${ }^{5-7}$ Here, we present the case of a female who developed ST-elevation myocardial infraction 30 minutes after ingesting sumatriptan for her migrainous symptoms. Triptan-induced vasospasm and infraction must be considered in patients with recent migraine treatment, even in those without cardiac risk factors.

\section{CASE REPORT}

A 45-year-old female presented to a community health center emergency department after having abrupt onset of severe retrosternal chest pain approximately 30 minutes after oral ingestion of $50 \mathrm{mg}$ sumatriptan advised by family physician for her migraine. She had a past medical history of migraine for which she took naproxen and domperidone. She had no history of coronary artery disease (CAD), diabetes mellitus, pulmonary disorders, tobacco abuse, cocaine use, or any recent illness or injury. She did not take exogenous estrogen nor had any family history of heart disease.

The electrocardiogram at presentation revealed an acute anterior ST-elevation myocardial infraction. The presence of headache delayed the decision to thrombolysis. She was given sublingual nitrate and referred to a tertiary center for consideration of primary angioplasty. During patient transport, her pain gradually improved after use of sublingual nitrate. 


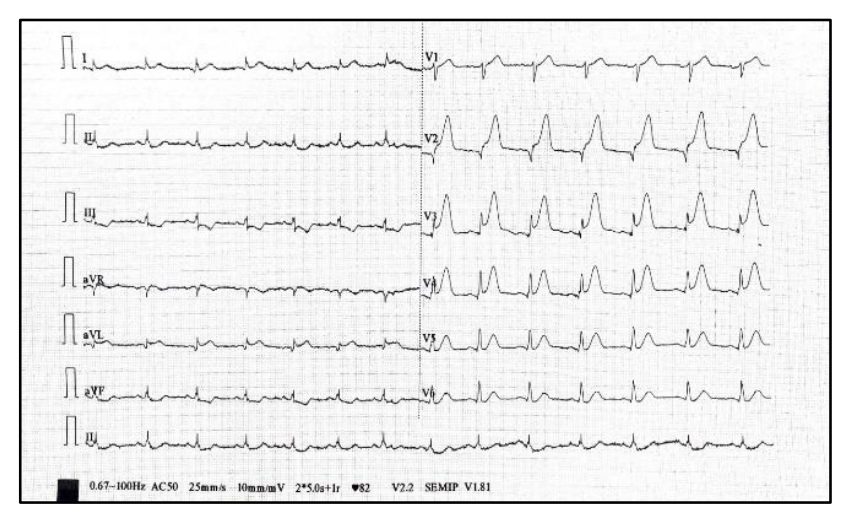

Figure 1: First Electrocardiogram (ECG) at presentation after use of oral sumatriptan.

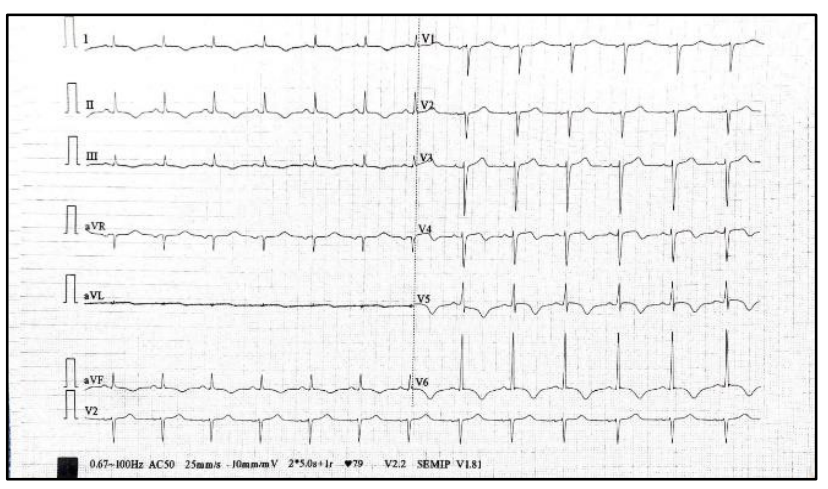

Figure 2: Second ECG done at cardiac center after use of sublingual nitrate.

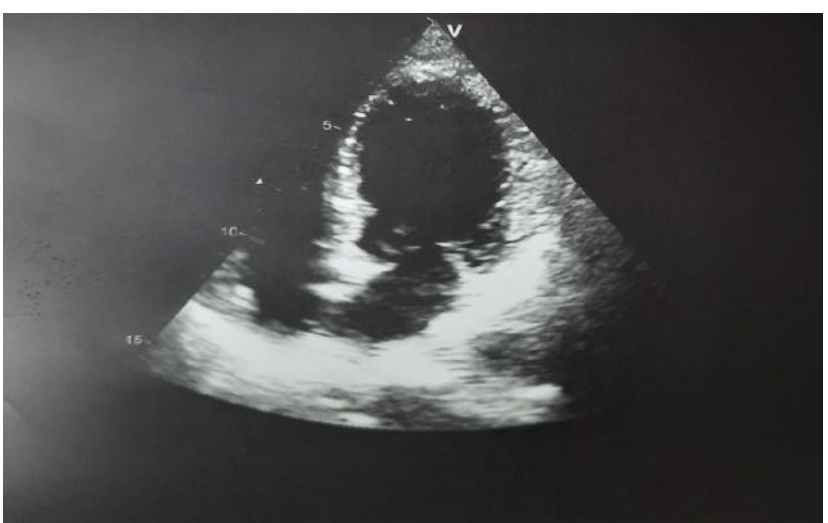

Figure 3: Transthoracic echocardiography- apical 4 chamber view showing dilated $\mathrm{LV}$ apex.

Once she arrived to the cardiac center, her chest pain had nearly resolved and she had re-perfused electrocardiographically, with a resultant Q-wave anterior myocardial infraction. Transthoracic echocardiography revealed severely impaired left ventricle function with an akinetic anteroapical segment. Early coronary angiography revealed a right dominant coronary circulation with normal epicardial coronaries. The patient was treated with standard secondary preventive therapies and advised to permanently avoid triptan use.

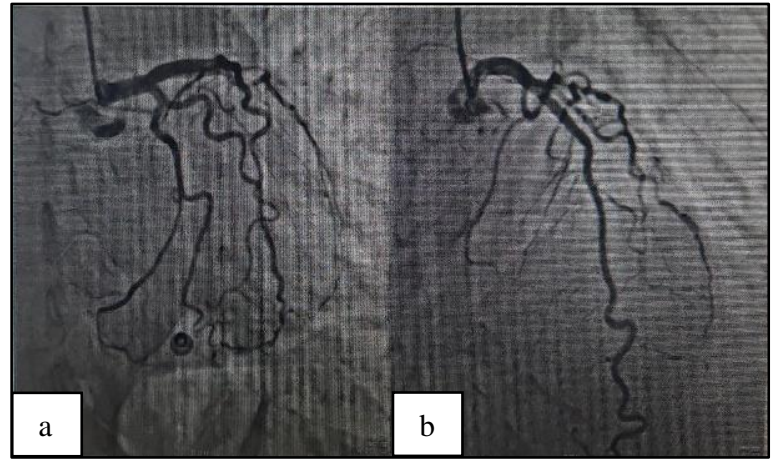

Figure 4: Coronary angiogram (a) RAO caudal view, (b) AP cranial view showing normal coronary arteries.

\section{DISCUSSION}

Sumatriptan belongs to the anti-migraine medication class called the triptans, which targets the 5-hydroxytryptamine (5-HT1) serotonin receptor in vascular smooth muscle. Initially, these medications were believed to abort migraines by targeting the vasoconstricting 5-HT1 receptors solely in the cerebral vasculature. ${ }^{8}$ Coronary circulation was believed to possess only serotonin 5-HT2 receptors, ensuring that coronary vasoconstriction would be aboided in triptan use. Despite this, there have been studies showing vasoconstrictive effects in the coronary circulation with the injectable form of these medications. ${ }^{9}$ There have been few reports of patients having myocardial ischemia or infraction with the oral form of sumatriptan, as in this case, with even fewer showing coronary angiographic evidence of coronary spasm. ${ }^{10-12}$

Earlier reports have described triptan-related myocardial infraction in the context of atheromatous coronary artery disease, after parenteral triptan use, or vasospastic disease. ${ }^{5-7}$ Patients with coronary artery disease may be more susceptible to the vasomotor effect of sumatriptan and related drugs through increased expression of coronary hydroxytryptamine receptors, and triptan therapy is not recommended in these individuals. ${ }^{13}$ To our knowledge this is the first report of myocardial infraction after oral triptan use in a patient with normal coronary arteries from India.

\section{CONCLUSION}

Our case suggests that normal cardiac evaluation does not guarantee safety, so family physician should counsel the patient about the potential cardiovascular risk of sumatriptan, even if there is no prior history of CAD. If there are cardiac risk factors, this medication should be avoided, or first attempted under close medical supervision.

Funding: No funding sources Conflict of interest: None declared

Ethical approval: Not required 


\section{REFERENCES}

1. Cady RK, Wendt JK, Kirchner JR. The treatment of acute migraine with subcutaneous sumatriptan. JAMA. 1991;265:2831-5.

2. The Subcutaneous Sumatriptan International Study Group. Treatment of migraine attacks with sumatriptan. N Engl J Med. 1991;325:316-21.

3. Stricker BH. Coronary vasospasm and sumatriptan. BMJ. 1002;305:118.

4. Davies MB, Krishnan A. Atrial fibrillation induced by sumatriptan. Cephalalgia. 2005;25:924-5.

5. O'Connor P, Gladstone P. Oral sumatriptanassociated transmural myocardial infraction. Neurol. 1995;45:2274-6.

6. Ottervanger JP, Pealman HJ, Boxma GL. Transmural myocardial infraction with sumatriptan. Lancet. 1993;341:861-2.

7. Plosay JJ, O’Connell TX. Acute coronary vasospasm resulting from sumatriptan administration in a patient with Raynaud's disease. Hosp Physician. 2002;38:514.

8. VanDenBrink MA, Reekers M, Bax WA. Coronary side-effect potential of current and prospective antimigraine drugs. Circulation. 1998;98(1):25-30.

9. Mikhail GW, Airoldi F, Columbo A. Acute myocardial infraction following the use of antimigraine therapy. J Invasive Cardiol. 2004;16(10):602-3.

10. Inman W, Kubota K. Cardiorespiratory distress after sumatriptan given by ingestion. BMJ. 1992;305(6855):713-4.

11. Laine K, Raasalkka T. Fatal cardiac arrhythmia after oral sumatriptan. Headache. 1999;39(7):511-2.

12. Villalon CM, Centurion D. Cardiovascular responses produced by 5-hydroxytriptamine: a pharmacological update on the receptors/mechanisms involved in therapeutic implications. Arch Pharmacol. 2007;376(1-2):45-63.

13. McIntyre PD, Bhargava B, Hogg KJ. The effect of subcutaneous sumatriptan on the systemic, pulmonary and coronary circulation. Circulation. 1993;87:401-5.

Cite this article as: Sahu I, Ruhela M, Ola RK. Acute ST-elevation myocardial infraction after use of oral sumatriptan: a rare presentation. Int J Basic Clin Pharmacol 2020;9:1746-8. 